\title{
International Genetic Evaluations of Holstein Sires for Milk Somatic Cell and Clinical Mastitis
}

\author{
T. Mark, W. F. Fikse, U. Emanuelson, and J. Philipsson \\ Interbull Centre, \\ Department of Animal Breeding and Genetics, \\ Swedish University of Agricultural Sciences \\ 75007 Uppsala, Sweden
}

\begin{abstract}
International genetic evaluations for milk somatic cell and clinical mastitis have been implemented on a routine basis by Interbull. This paper examines possible genetic consequences of such evaluations. Holstein data from 12 countries were used for this purpose. Trait definitions and national genetic evaluation procedures were first summarized and showed that differences between countries existed. Estimated genetic correlations among milk somatic cell in these countries ranged from 0.47 to 0.97 , with a median of 0.88 . Estimated genetic correlations among clinical mastitis in three Nordic countries ranged from 0.59 to 0.83 , and estimated genetic correlations between clinical mastitis in the three Nordic countries and milk somatic cell in the non-Nordic countries ranged from 0.37 to 0.78 with a median of 0.55 . Bulls without daughter information in the Nordic countries had low reliabilities on the Nordic clinical mastitis scales. International genetic evaluations for milk somatic cell and clinical mastitis enable a broader selection among foreign bulls, and higher selection differentials were found when using international evaluations compared with national evaluations.
\end{abstract}

(Key words: milk somatic cell, clinical mastitis, international genetic evaluations, Interbull, MACE, genetic correlation, Holstein)

Abbreviation key: CAN $=$ Canada CHE $=$ Switzerland; CM = clinical mastitis; DEU = Germany; DNK = Denmark; EDC = effective daughter contributions; EM = expectation-maximization $; \mathbf{E S T}=$ Estonia $; \mathbf{F I N}=$ Finland; FRA = France; GBR = The United Kingdom; ISR $=$ Israel; $\mathbf{M A C E}=$ multiple-trait across-country evaluation; NLD = The Netherlands; $\mathbf{S C}=$ milk somatic cell; $\mathbf{S D}=$ selection differential; $\mathbf{S W E}=$ Sweden; $\mathbf{U S A}=$ The United States.

Received January 16, 2002.

Accepted April 10, 2002.

Corresponding author: T. Mark; e-mail: Thomas.Mark@hgen. slu.se.

\section{INTRODUCTION}

Dairy cattle breeding is an international business, where the same elite sires are used in several countries. The internationalization of dairy cattle breeding requires that bulls can be compared across countries for all breeding goal traits, since incomplete information about genetic values for breeding goal traits of some selection candidates can lead to wrong selection decisions.

Functional traits are associated with efficiency of production by their direct influence on costs of production and are generally considered to be an important factor in maximizing profit from dairy operations worldwide. As a consequence, several countries perform national genetic evaluations for various functional traits (Groen et al., 1997). However, information to support objective selection decisions concerning foreign sires have been limited to the information from Interbull's routine evaluations for production and conformation traits until recently. International genetic evaluations should be considered to enable comparisons between sires across countries for functional traits as well as for all other breeding goal traits.

An international genetic evaluation for traits directly related to udder health, i.e., clinical mastitis $(\mathbf{C M})$ and milk somatic cells (SC), has been investigated (Mark et al., 2000a, 2000b), and a routine international evaluation was implemented by Interbull in May 2001. The genetic consequences of the introduction of such evaluations are expected to benefit the global dairy cattle breeding industry, but it is not known to what extent.

The aim of this study was to investigate and quantify possible impacts of international genetic evaluations for $\mathrm{SC}$ and $\mathrm{CM}$ on components related to genetic progress and to discuss the methodology used for such evaluations.

\section{MATERIALS AND METHODS}

National genetic evaluation results of Holstein bulls for SC were obtained from Canada (CAN), Switzerland (CHE), Germany (DEU), Denmark (DNK), Estonia 
Table 1. Trait definition and summary of national genetic evaluation procedures for milk somatic cell (SC) and clinical mastitis (CM) in countries providing data.

\begin{tabular}{|c|c|c|c|c|c|c|c|}
\hline Trait & Country & Trait definition & Data since & DIM & \# Parities & Model $^{1}$ & $\mathrm{~h}^{2}$ \\
\hline \multirow{8}{*}{$\mathrm{SC}$} & CAN & $\log _{2}$ test-day SCC & 1988 & $5-305$ & 3 & $\mathrm{MT}^{2} \mathrm{ML}$ RR TDM & 0.29 \\
\hline & CHE & $\log _{2}$ test-day SCC & 1995 & 4365 & 3 & ST ML FR TDM & 0.31 \\
\hline & DEU & $\log _{2}$ test-day SCC & 1990 & 4365 & 3 & ST ML FR TDM & 0.20 \\
\hline & EST & $\log _{2}$ test-day SCC & 1994 & 4365 & 3 & ST ML FR TDM & 0.12 \\
\hline & FIN & Lact. mean of $\log _{10}$ test-day SCC & 1978 & $5-305$ & 3 & ST R AM & 0.15 \\
\hline & FRA & Lact. mean of $\log _{2}$ test-day SCC & 1989 & $5-350$ & 3 & ST R AM & 0.15 \\
\hline & SWE & Lact. mean of $\log _{10}$ test-day SCC & 1982 & $5-150$ & 1 & ST SM & 0.08 \\
\hline & USA & Lact. mean of $\log _{2}$ test-day SCC & 1987 & $6-305$ & 5 & ST R AM & 0.10 \\
\hline \multirow[t]{3}{*}{ CM } & DNK & Clinical mastitis ${ }^{3}$ scored in 2 categories & 1990 & $-10-305$ & 3 & $\mathrm{MT}^{3} \mathrm{ML} \mathrm{SM}$ & 0.04 \\
\hline & FIN & $\begin{array}{l}\text { Clinical mastitis and culling due to } \\
\text { udder diseases scored in } 2 \text { categories }\end{array}$ & 1983 & $-7-150$ & 3 & ST R SM & 0.05 \\
\hline & SWE & $\begin{array}{l}\text { Clinical mastitis and culling due to } \\
\text { udder diseases scored in } 2 \text { categories }\end{array}$ & 1983 & $-10-150$ & 1 & ST SM & 0.02 \\
\hline
\end{tabular}

${ }^{1} \mathrm{MT}=$ Multi-trait (biologically different traits analyzed simultaneously); $\mathrm{ST}=$ single-trait; $\mathrm{ML}=$ multi-lactation; $\mathrm{R}=$ repeatability model; $\mathrm{TDM}=$ animal model using test-day records; $\mathrm{AM}=$ animal model; $\mathrm{SM}=$ sire model; $\mathrm{RR}=$ random regression; $\mathrm{FR}=$ fixed regression .

${ }^{2}$ Milk, fat, and protein yield analyzed with SC.

${ }^{3} \mathrm{SC}$ in first lactation, $\mathrm{CM}$ in three lactations (four distinct time periods) and three udder conformation traits, analyzed simultaneously (Nielsen et al., 2000).

(EST), Finland (FIN), France (FRA), The United King$\operatorname{dom}($ GBR), Israel (ISR), The Netherlands (NLD), Sweden (SWE) and The United States (USA). Furthermore, national genetic evaluation results of Holstein bulls for CM were available from three Nordic countries (DNK, FIN, and SWE). All countries provided data, where the traits were not analyzed simultaneously with biologically different traits, except for data from CAN and DNK (Table 1).

\section{International Genetic Evaluation Steps and Data Edits}

The international genetic evaluation consisted of two main steps in which different data edits were imposed. These two steps were: 1) Deregression of national genetic evaluation results and estimation of genetic correlations, and 2) deregression of national genetic evaluation results, sire variance estimation, and prediction of international genetic evaluation results. A common requirement in both of these two steps was that data comprised AI bulls with daughters in at least 10 herds (number of daughters were used if number of herds were missing for a bull). In addition to the 10 herds, bulls were required to have at least 50 daughters for CM (but not for SC).

A well-connected subset of bulls having evaluations in more than one country (common bulls) as well as bulls that belong to $3 / 4$-sib groups that have members with evaluations in more than one country were created and used to estimate genetic correlations.
In the deregression preceding prediction of international breeding values, in estimation of sire variances, and in prediction of international breeding values (step 2 ), bulls born since 1984 were considered. National evaluation results realized from imported semen were required to be based on at least 75 daughters in 50 herds to be included. Imported bulls were also required to have an evaluation based on first-crop daughters in another country in order to avoid selection bias. These data edits followed those currently used in Interbull's routine evaluation for udder health traits.

Two runs were conducted. Run 1 comprised SC information from all 12 countries, and Run2 comprised CM information from the three Nordic countries (DNK, FIN, SWE) and SC information from the remaining nine countries. Genetic correlations were estimated in two multivariate (12-trait) analyses corresponding to Run1 and Run2.

Genetic ties judged by the number of common bulls and 3/4-sib families were generally strong among countries except for EST, FIN, and ISR (Table 2). The Nordic countries lost some ties in Run2 compared to Run1 due to a more strict requirement on number of daughters and due to fewer observations on CM compared with SC in FIN and SWE (Table 3). The number of common bulls in Run2 for DNK, FIN, and SWE decreased with 4 to $38 \%$ compared with Run1 except for the number of common bulls between DNK and EST, which decreased from 6 to 4. For the other countries SC was used and the numbers were as in Table 2 . 
Table 2. Number of common bulls (above diagonal) and 3/4-sib families (below diagonal) between countries included in estimation of genetic correlations for milk somatic cell.

\begin{tabular}{lrrrrrrrrrrrr}
\hline & CAN & CHE & DEU & DNK & EST & FIN & FRA & GBR & ISR & NLD & SWE & USA \\
\hline CAN & & 126 & 344 & 120 & 4 & 8 & 421 & 486 & 10 & 297 & 173 & 999 \\
CHE & 167 & & 144 & 61 & 1 & 6 & 155 & 140 & 4 & 124 & 95 & 143 \\
DEU & 764 & 181 & & 173 & 21 & 30 & 540 & 393 & 22 & 677 & 222 & 617 \\
DNK & 383 & 126 & 766 & & 6 & 25 & 148 & 142 & 7 & 141 & 161 & 153 \\
EST & 47 & 15 & 52 & 38 & & 0 & 7 & 6 & 0 & 19 & 3 & 10 \\
FIN & 27 & 18 & 42 & 43 & 6 & & 30 & 22 & 3 & 24 & 37 & 31 \\
FRA & 661 & 162 & 910 & 513 & 51 & 49 & & 370 & 22 & 472 & 203 & 736 \\
GBR & 440 & 139 & 551 & 345 & 40 & 37 & 530 & & 19 & 390 & 195 & 433 \\
ISR & 21 & 8 & 27 & 14 & 2 & 4 & 29 & 21 & & 33 & 13 & 31 \\
NLD & 413 & 139 & 908 & 370 & 45 & 41 & 776 & 451 & 38 & & 193 & 569 \\
SWE & 243 & 111 & 342 & 292 & 22 & 51 & 313 & 237 & 16 & 250 & & 275 \\
USA & 1117 & 168 & 1156 & 513 & 57 & 49 & 1251 & 564 & 36 & 851 & 385 & \\
\hline
\end{tabular}

\section{METHODS}

National breeding values were first deregressed within country using a single-trait sire model (Jairath et al., 1998). Sire variances were estimated within country using a single trait expectation-maximization (EM) REML procedure (Sullivan, 1999). Genetic correlations were estimated with an EM-REML algorithm applied on a reduced set of mixed model equations (Klei and Weigel, 1998) corresponding to the model used for international genetic evaluations. Multi-trait across country evaluations (MACE) were used to combine deregressed national genetic evaluation results $\left(\mathbf{y}_{\mathbf{i}}\right)$ from several countries (i) into international sire evaluations $\left(\mathbf{s}_{\mathbf{i}}\right)$ as follows (Schaeffer, 1994):

$$
\mathbf{y}_{\mathrm{i}}=\mu_{\mathrm{i}} \mathbf{1}+\mathbf{Z}_{\mathrm{i}} \mathbf{Q} \mathbf{g}_{\mathrm{i}}+\mathbf{Z}_{\mathrm{i}} \mathbf{s}_{\mathrm{i}}+\mathbf{e}_{\mathrm{i}}
$$

where

$$
\begin{aligned}
& \mathbf{y}_{\mathrm{i}}=\text { vector of deregressed national evaluation } \\
& \text { results for country } \mathrm{i} ;
\end{aligned}
$$

$$
\begin{aligned}
\mu_{\mathrm{i}} & =\text { fixed effects of country mean; } \\
\mathbf{g}_{\mathrm{i}}= & \text { random vector of genetic group effects; } \\
\mathbf{s}_{\mathrm{i}}= & \text { random sire vector of international sire } \\
& \text { evaluations; } \\
\mathbf{e}_{\mathrm{i}}= & \text { random residual vector; } \\
\mathbf{Z}_{\mathrm{i}} & =\text { sire incidence matrix; } \\
\mathbf{Q}= & \text { matrix assigning sires in } \mathbf{s} \text { to group effects } \\
& \text { in } \mathbf{g} .
\end{aligned}
$$

The joint distribution of the random variables was assumed to be multivariate normal with $\operatorname{var}(\mathbf{s})=\mathbf{G}_{0} \otimes$ $\mathbf{A}, \operatorname{var}(\mathbf{g})=\mathbf{I} \otimes \mathbf{G}_{0}$ and $\operatorname{var}\left(\mathbf{e}_{\mathrm{i}}\right)=\mathbf{R}_{\mathrm{i}} . \mathbf{G}_{0}$ is the genetic (co)variance matrix between traits measured in different countries; $\mathbf{A}$ is the additive genetic relationship matrix relating bulls with their sires, maternal grandsires, and maternal grandams; $\mathbf{R}_{\mathrm{i}}$ is the (co)variance matrix among elements of $\mathbf{e}_{\mathrm{i}}$ and was assumed to be a diagonal matrix with elements equal to the ratio of residual variance relative to effective daughter contributions (EDC) for the jth or j'th observation in country $\mathrm{i}: \mathbf{R}_{\mathrm{i}}=\operatorname{diag}\left(\sigma_{\mathrm{ei}}^{2} / \mathrm{EDC}_{\mathrm{ij}}\right)$. EDC were computed according

Table 3. Number of bulls included in parameter estimation (PAR) and included in prediction of international breeding values (EVAL).

\begin{tabular}{llcrr}
\hline Trait $^{1}$ & Country & PAR (Run1) & PAR (Run2) & EVAL \\
\hline SC & CAN & 4384 & 4374 & 4923 \\
& CHE & 321 & 321 & 338 \\
& DEU & 6163 & 6057 & 9654 \\
& DNK & 3057 & $\ldots$ & 4001 \\
& EST & 123 & 123 & 239 \\
& FIN & 155 & $\ldots$ & 590 \\
& FRA & 6661 & 6646 & 7100 \\
& GBR & 1725 & 1725 & 1671 \\
& ISR & 50 & 50 & 482 \\
& NLD & 4072 & 4065 & 5415 \\
& SWE & 1061 & $\ldots .794$ & 1295 \\
CM & USA & 14,818 & 2219 & 16,400 \\
& DNK & $\ldots$ & 94 & 3441 \\
& FIN & $\ldots$ & 892 & 556 \\
& SWE & $\ldots$ & & 1275 \\
\hline
\end{tabular}

\footnotetext{
${ }^{1} \mathrm{SC}=$ Milk somatic cell; $\mathrm{CM}=$ clinical mastitis.
} 
to Fikse and Banos (2001), and reliabilities for international breeding values were approximated according to Harris and Johnson (1998).

\section{Genetic Groups}

Genetic groups for missing ancestors were formed based on birth year, population of origin, and selection path. Populations were defined following country borders, and selection paths were sires, maternal grandsires, and maternal grandams, respectively. Groups were required to include a minimum of 30 animals, and it was therefore necessary to assign missing ancestors with different birth years coming from different countries to the same groups. Distinct selection paths were always maintained.

\section{Selection Differentials and Genetic Trends}

Selection differentials (SD) were computed as the difference between the mean evaluation result of the top 10 ranking bulls and the mean national evaluation result relative to the genetic standard deviation for the trait:

$$
\mathrm{SD}=\left(\overline{\mathrm{y}}_{10}-\mu\right) / \sigma_{\mathrm{g}},
$$

where

$$
\begin{aligned}
\mathrm{SD}= & \text { selection differential } \\
\overline{\mathrm{y}}_{10}= & \text { mean evaluation result for the top } 10 \\
& \text { bulls } \\
\mu= & \text { mean national evaluation result } \\
\sigma_{\mathrm{g}}= & \text { estimated genetic standard deviation. }
\end{aligned}
$$

Genetic trends were computed for SC and CM in SWE. The Swedish scales were chosen, because both $\mathrm{SC}$ and $\mathrm{CM}$ were available, and because the two traits were expressed on a similar scale, i.e., both SC and CM in SWE were expressed as relative breeding values with mean 100 and standard deviation 7 (high values are favorable). The mean international genetic evaluation result weighted by the total number of informative daughters across countries for all bulls with an official evaluation were computed for bulls within birth year as

$$
\overline{\mathrm{s}}_{\mathrm{t}}=\Sigma_{\mathrm{j}}\left(\mathrm{s}_{\mathrm{tj}} \times \Sigma_{\mathrm{i}} \mathrm{n}_{\mathrm{ij}}\right) / \Sigma_{\mathrm{j}} \Sigma_{\mathrm{i}} \mathrm{n}_{\mathrm{ij}},
$$

where $\mathrm{s}_{\mathrm{tj}}$ is the international genetic evaluation result on the Swedish CM scale for bull $j$; $t \in\{1985,1986, \ldots$, 1996\} indicates the birth year of bull $j$ and $n_{i j}$ is the actual number of daughters of bull $j$ considered in the national genetic evaluation in country $i$. The total number of daughters across countries was used as weighting factor to illustrate the genetic trends in commercial cow populations.

\section{RESULTS AND DISCUSSION}

\section{Estimated Genetic Correlations}

Estimated genetic correlations were generally high among SC from most countries and ranged from 0.47 to 0.97 with a median value of 0.88 (Table 4). True genetic correlations less than unity can generally be explained by differences in 1) production environments (genotype $\times$ environment interaction) and in 2) trait definitions. Furthermore, differences in, e.g., national genetic evaluation procedures, weak genetic ties (Klei and Weigel, 1998), and erroneous identification (Banos et al., 2001) can cause the estimated genetic correlation to be less than unity. Estimated genetic correlations between ISR and other countries were lower compared with all other estimates in Table 4, which may be explained by a different production environment in ISR, the fact that five parities were considered in ISR (Table 1) and that ISR had few genetic ties with most other countries in this study (Table 2). GBR and USA also considered the first five parities. The estimated genetic correlation between USA and ISR (0.86) was higher than any estimated correlation between ISR and the rest of the countries, and it was based on 31 common bulls, which were more than ISR had in common with the rest of countries, respectively. Similarly, the estimated genetic correlation between SC in DNK and SC in SWE (0.97) was higher than any other estimated correlation involving these two countries. Both DNK and SWE only considered data from the first half of the first lactation, but evaluation procedures differed, since DNK used a multiple-trait model with CM and SWE used a single-trait model (Table 1).

Estimated correlations among SC in different countries were consistent between Run1 and Run2 (Tables 4 and 5). Estimated correlations between SC in one country and CM in a different country were moderate and ranged from 0.37 to 0.78 with a median value of 0.57. Trait definition and evaluation model for $\mathrm{CM}$ were different between the three Nordic countries, and estimated correlations among CM in two different countries ranged from 0.59 to 0.83 . EST, FIN, and ISR often had weak genetic ties with other countries (Table 2), and, consequently, estimated genetic correlations are less precise for these countries.

Estimated genetic correlations presented in this study were within the range of those presented in the literature. A number of studies have estimated correlations between national genetic evaluation results adjusted for reliabilities (e.g., Mrode and Swanson, 1997; Rogers et al., 1998; Grignola and Schaeffer, 2000), but 
Table 4. Estimated genetic correlations ${ }^{1}$ among milk somatic cell in 12 different countries.

\begin{tabular}{|c|c|c|c|c|c|c|c|c|c|c|c|c|}
\hline & CAN & CHE & DEU & DNK & EST & FIN & FRA & GBR & ISR & NLD & SWE & USA \\
\hline CAN & & 0.89 & 0.84 & 0.79 & 0.76 & 0.83 & 0.92 & 0.92 & 0.67 & 0.93 & 0.87 & 0.92 \\
\hline CHE & & & 0.95 & 0.87 & 0.93 & 0.87 & 0.96 & 0.94 & 0.65 & 0.96 & 0.88 & 0.88 \\
\hline DEU & & & & 0.79 & 0.84 & 0.76 & 0.90 & 0.87 & 0.69 & 0.91 & 0.82 & 0.85 \\
\hline DNK & & & & & 0.88 & 0.91 & 0.90 & 0.89 & 0.67 & 0.86 & 0.97 & 0.86 \\
\hline EST & & & & & & 0.83 & 0.91 & 0.88 & 0.62 & 0.89 & 0.86 & 0.82 \\
\hline FIN & & & & & & & 0.89 & 0.88 & 0.47 & 0.87 & 0.93 & 0.77 \\
\hline FRA & & & & & & & & 0.97 & 0.66 & 0.95 & 0.92 & 0.92 \\
\hline GBR & & & & & & & & & 0.60 & 0.97 & 0.92 & 0.90 \\
\hline ISR & & & & & & & & & & 0.62 & 0.70 & 0.86 \\
\hline NLD & & & & & & & & & & & 0.90 & 0.89 \\
\hline SWE & & & & & & & & & & & & 0.91 \\
\hline USA & & & & & & & & & & & & \\
\hline
\end{tabular}

${ }^{1}$ The direction of the data was standardized so that a high breeding value means high somatic cell count in all countries.

these studies were based on data from a limited number of countries and used methodology, which only consider evaluation results from common bulls, i.e., methods based on Calo et al. (1973). Mark et al. (2000b) estimated genetic correlations between SC and CM among nine of the same Holstein populations as represented in this study using different EM-REML based precedures. That study showed good agreement between genetic correlations estimated according to Klei and Weigel (1998) and those estimated according to Sigurdsson et al. (1996), when genetic ties were strong (more than 30 common bulls). However, estimated correlations were generally lower with the method of Sigurdsson et al. (1996) compared with those obtained using the method of Klei and Weigel (1998), when genetic ties were weak (Mark et al., 2000b).

The correlation matrix for SC (Table 4) had one dominating eigenvalue that explained $86.4 \%$ of the total additive genetic variation, and the remaining 11 eigenvalues only explained from 5.3 to $0.1 \%$ of the variation, respectively. This may suggest that largely the same set of genes govern expression of SC across countries. In comparison, the largest eigenvalue for the correlation matrix for SC and CM (matrix in Table 5) explained $75.5 \%$ of the additive genetic variation, whereas the remaining eigenvalues explained 8.8 to $0.2 \%$ of the variation, respectively.

\section{Genetic Consequences of International Evaluations for SC and $\mathrm{CM}$}

Selection differentials presented in Table 6 confirmed that higher genetic progress can be achieved when selecting among all bulls included in the international evaluation compared with selection among bulls included in the respective national evaluations. This is primarily the result of sufficiently high genetic correlations between countries and the much larger genetic pool to select from globally compared with nationally. Relatively small populations such as CHE, EST, and ISR had relatively low SD for national SC evaluations (0.88 to 0.92 ) compared with the median value of 1.29 . FRA, GBR, and NLD had the highest average genetic correlation with other countries (0.89 to 0.90 in Run1),

Table 5. Estimated genetic correlations ${ }^{1}$ among clinical mastitis in Nordic countries (DNK, FIN and SWE) and milk somatic cell in non-Nordic countries.

\begin{tabular}{|c|c|c|c|c|c|c|c|c|c|c|c|c|}
\hline & CAN & $\mathrm{CHE}$ & DEU & DNK & EST & FIN & FRA & GBR & ISR & NLD & SWE & USA \\
\hline CAN & & 0.89 & 0.85 & 0.52 & 0.77 & 0.63 & 0.92 & 0.92 & 0.68 & 0.93 & 0.60 & 0.92 \\
\hline CHE & & & 0.95 & 0.55 & 0.92 & 0.42 & 0.96 & 0.94 & 0.63 & 0.97 & 0.54 & 0.88 \\
\hline DEU & & & & 0.62 & 0.82 & 0.43 & 0.90 & 0.87 & 0.68 & 0.91 & 0.56 & 0.85 \\
\hline DNK & & & & & 0.57 & 0.57 & 0.52 & 0.47 & 0.78 & 0.50 & 0.86 & 0.63 \\
\hline EST & & & & & & 0.37 & 0.91 & 0.89 & 0.62 & 0.89 & 0.56 & 0.84 \\
\hline FIN & & & & & & & 0.48 & 0.49 & 0.55 & 0.50 & 0.72 & 0.59 \\
\hline FRA & & & & & & & & 0.97 & 0.64 & 0.95 & 0.55 & 0.92 \\
\hline GBR & & & & & & & & & 0.58 & 0.97 & 0.55 & 0.90 \\
\hline ISR & & & & & & & & & & 0.61 & 0.66 & 0.84 \\
\hline NLD & & & & & & & & & & & 0.58 & 0.88 \\
\hline SWE & & & & & & & & & & & & 0.62 \\
\hline USA & & & & & & & & & & & & \\
\hline
\end{tabular}

\footnotetext{
${ }^{1}$ The direction of the data was standardized so that a high breeding value means high SCC and incidence of clinical mastitis, respectively, in all countries.
} 
and these countries also had the highest SD for international evaluations (1.32 to 1.43 ), whereas ISR had the lowest average genetic correlation with other countries in Run1 (0.66) and also the lowest SD for international evaluation results in Run1.

The differences in SD obtained from national and those obtained from international evaluations were a result of different bulls appearing in the top 10 national compared with top 10 international rankings (Table 6). For Run1, there were from 0 to 5 bulls in common between national and international top 10 rankings. For Run2, there were up to seven bulls in common between top 10 national and top 10 international rankings (CM in DNK). Relatively many bulls were in common in top 10 national and international rankings for $\mathrm{CM}$ in DNK, because genetic correlations were low, with all traits except with CM in SWE, and because the national breeding values were more precisely estimated (higher heritability and median EDC) for CM in DNK compared with CM in Sweden. EDC are not easily comparable across countries, since they depend on an assumed heritability. A higher heritability results in lower EDC (Fikse and Banos, 2001), but a combination of both higher heritability and higher EDC lead to higher reliability of evaluation results and higher selection differential. The heritability for CM in DNK was twice as high as for CM in SWE (Table 1), and the median EDC was 270 for CM in DNK and 140 for CM in SWE. This also explains why the SD for national and international evaluations were essentially the same (1.22) for CM in DNK and why only one bull was in common between national and international top 10 rankings for CM in SWE. CM in FIN had the lowest SD for international evaluation results in Run2 (0.92). This is explained by relatively low genetic correlations between CM in FIN and all other traits (0.37 to 0.72) and a relative low number of evaluated bulls in FIN.

Selection differentials were generally higher for SC compared with $\mathrm{CM}$ due to the much larger number of bulls with national evaluations for SC compared with CM (Table 3) and due to the higher heritabilities for $\mathrm{SC}$ and genetic correlations among SC compared with CM. However, resistance to clinical mastitis is considered to be the main breeding goal trait in many countries, and the improvement in SC should then be translated in terms of the correlated response in CM. Assuming a genetic correlation of 0.7 between $\mathrm{SC}$ and $\mathrm{CM}$ within non-Nordic countries, the expected correlated selection differentials for CM based on selection on international evaluations for SC ranged from 0.81 to 1.00 , which is less than selection differentials for CM in DNK and SWE and within the range of the selection differential for CM in FIN. These expected correlated selection differentials for CM based on selection for SC are lower than the expected correlated selection differential for $\mathrm{CM}$ in a non-Nordic country, if selection is for $\mathrm{CM}$ on the DNK scale and a genetic correlation of 0.85 is assumed between CM in DNK and CM in a non-Nordic country $(1.22 \times 0.85=1.04)$. This illustrates that direct (or closer to direct) selection is more advantageous than indirect selection here.

Selection differentials in Table 6 were based on all evaluated bulls, but often countries have specific minimum requirements for publication of breeding values based on, e.g., their reliability. Thus, the difference in realized selection differential between national and international evaluations may be lower than those shown here. Furthermore, main selection emphasis is on production traits, which are unfavorably correlated with CM ( 0.45) and less unfavorably correlated with SC

Table 6. Selection differentials for international (INT) and national (NAT) evaluation results and number of bulls in common (CS) between top 10 international and national rankings. ${ }^{1}$

\begin{tabular}{llllllll}
\hline & \multicolumn{3}{c}{ Run1 } & & & \multicolumn{2}{c}{ Run2 } \\
\cline { 2 - 3 } Country & INT & NAT & CS & & INT & NAT & CS \\
\hline CAN & 1.27 & 1.24 & 3 & 1.27 & 1.24 & 3 \\
CHE & 1.27 & 0.92 & 0 & 1.27 & 0.92 & 0 \\
DEU & 1.30 & 1.26 & 5 & 1.30 & 1.26 & 3 \\
DNK & 1.24 & 1.16 & 2 & 1.22 & 1.22 & 7 \\
EST & 1.19 & 0.88 & 0 & 1.19 & 0.88 & 2 \\
FIN & 1.28 & 1.04 & 0 & 0.92 & 0.90 & 5 \\
FRA & 1.35 & 1.19 & 0 & 1.35 & 1.19 & 1 \\
GBR & 1.32 & 1.09 & 2 & 1.31 & 1.09 & 2 \\
ISR & 1.16 & 0.92 & 1 & 1.17 & 0.92 & 1 \\
NLD & 1.43 & 1.22 & 1 & 1.43 & 1.22 & 1 \\
SWE & 1.30 & 1.03 & 1 & 1.18 & 0.82 & 1 \\
USA & 1.31 & 1.23 & 3 & 1.31 & 1.23 & 3 \\
\hline
\end{tabular}

${ }^{1}$ Run1: Milk somatic cell data from all 12 countries analyzed simultaneously. Run2: Clinical mastitis data from Nordic countries analyzed with milk somatic cell data from non-Nordic countries. 
( 0.15) (e.g., Mrode and Swanson, 1996; Rupp and Boichard, 1999; Heringstad et al., 2000). With main selection emphasis on production traits, a deterioration of especially CM could therefore be feared.

The genetic level of both SC and CM in the global Holstein population have been quite constant during the past $10 \mathrm{yr}$, but have deteriorated slightly for the past 2 or $3 \mathrm{yr}$ (Figure 1), although some differences were evident among countries (results not shown). The computed genetic trends reflected the average genetic levels in the global commercial cow population. Similar trends were obtained when breeding values on the Swedish scale were weighted with their reliabilities and when equal weights were put on each breeding value (results not shown).

These genetic trends indicate that selection emphasis on traits directly or indirectly related to udder health have been sufficient to counterbalance the negative effects of selection for increased production; at least until recently. Widespread use of individual bulls transmitting poor resistance to mastitis may explain the decrease in genetic level of CM and SC for bulls born in later years, but before national genetic evaluations for $\mathrm{SC}$ or CM were applied in some countries. Increased international trade, which may have focused on production traits, is another possible explanation for the decrease in genetic level of $\mathrm{CM}$, and to a lesser extent of $\mathrm{SC}$, in recent years.

International breeding values for bulls of domestic origin had higher reliability compared with international breeding values of foreign bulls (Table 7), because bulls tend to have more daughter information in their country of origin. Domestic bulls had relatively high

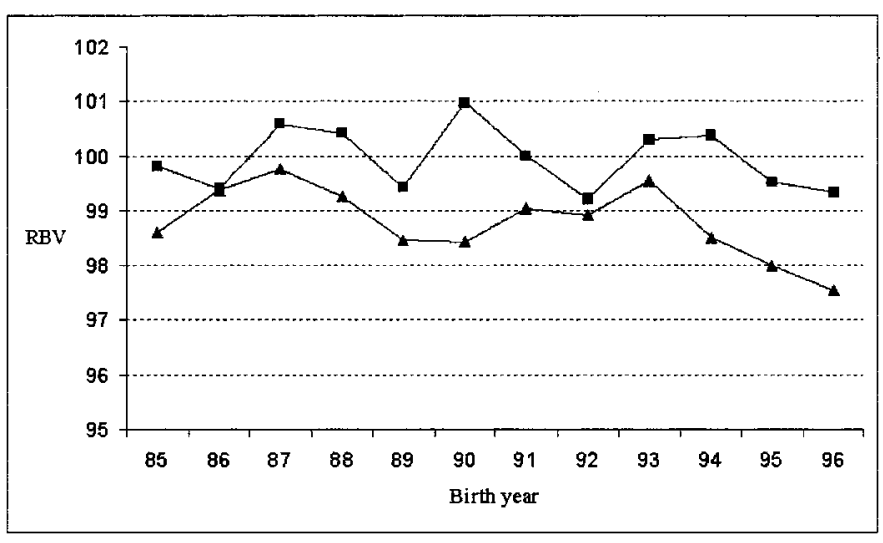

Figure 1. Global genetic trend in milk somatic cell $(\mathbf{\Delta})$ and clinical mastitis (ם) measured as mean international genetic evaluation results on Swedish scales weighted by total number of daughters in all 12 countries as a function of birth year of the bull. The number of bulls per birth year ranged from 2190 to 4662 . Milk somatic cell and clinical mastitis in Sweden were expressed as relative breeding values (RBV) and high values were favorable. reliabilities on average for SC in FIN (89.4\%), mainly because of relatively high median EDC in FIN (245). This value was substantially higher than the median EDC for SC in other countries, which ranged from 64 (USA) to 128 (ISR). Furthermore, domestic bulls in $\mathrm{CAN}, \mathrm{CHE}$, and DEU had relatively high reliabilities (82 to $86 \%$ ) mainly due to relatively high heritabilities for SC in these countries ( 0.20 to 0.31$)$. Domestic bulls in SWE had relatively low reliabilities for CM on average $(52.3 \%)$ mainly due to the low heritability for this trait (0.02). Foreign bulls had relative low reliabilities on average for SC in FIN (57.9\%) and especially for SC in ISR $(49.2 \%)$ mainly due to relative low genetic correlations with other countries (Table 7).

Table 7 further illustrates that foreign bulls had low average reliability on especially the Nordic CM scales (33 to 41\%), which is because the majority of bulls in the international evaluation did not have daughter information for $\mathrm{CM}$ in these countries, and prediction of breeding values for the majority of bulls was thus confined to correlated information.

Diversity among bulls to be selected in different countries can arise from different rankings for similar traits across countries and because of different relative economic values for different traits across countries. The percentage of bulls in common between the top 100 lists in two countries ranged from 24 to $87 \%$ in Run1, and there were 273 different bulls appearing in the 12 different top 100 lists. In Run2, the percentage of bulls in common between the top 100 lists in two countries ranged from 8 to $85 \%$, and there were 372 different bulls appearing in the 12 different top 100 lists. The larger number of bulls appearing in the 12 different top 100 lists for Run2 compared with Run1 were mostly found in the Nordic countries. As a comparison, 212 different bulls appeared in the top 100 lists for the same 12 Holstein populations in the May 2001 Interbull routine evaluation for milk production (264 different bulls for all 27 participating Holstein populations).

The introduction of international genetic evaluations for traits other than production also enables countries and individual farmers to base their selection decisions on a broader range of selection criteria in order to better comply with true breeding objectives, and differences in relative economic values among countries can lead to increased diversity in the bulls used across countries.

\section{General Discussion on Methodology Used}

The assumption of zero residual correlations in the MACE procedure described by Schaeffer (1994) prevents multiple traits from one country to be analyzed simultaneously, and current Interbull evaluations 
Table 7. Mean reliability (percentage) of international breeding values for Run1 and Run2 for bulls of domestic (DOM) and foreign (FOR) origin. ${ }^{1}$

\begin{tabular}{lllll}
\hline & \multicolumn{2}{c}{ Run1 } & \multicolumn{2}{c}{ Run2 } \\
\cline { 2 - 3 } Country & DOM & FOR & DOM & FOR \\
\hline CAN & 82.2 & 64.6 & 82.2 & 62.7 \\
CHE & 86.1 & 68.0 & 86.1 & 65.5 \\
DEU & 85.5 & 61.5 & 85.5 & 59.7 \\
DNK & 75.5 & 60.7 & 74.6 & 40.0 \\
EST & 70.7 & 60.3 & 70.6 & 57.8 \\
FIN & 89.4 & 57.9 & 79.9 & 32.8 \\
FRA & 80.9 & 67.9 & 80.9 & 64.5 \\
GBR & 73.1 & 67.6 & 73.1 & 64.5 \\
ISR & 77.0 & 49.2 & 78.0 & 48.8 \\
NLD & 78.4 & 67.0 & 52.3 & 63.7 \\
SWE & 74.3 & 65.1 & 69.2 & 40.6 \\
USA & 69.2 & 67.2 & 63.9 \\
\hline
\end{tabular}

${ }^{1}$ National origin was defined according to unique international identification. Run1: Milk somatic cell data from all 12 countries were analyzed simultaneously. Run2: Clinical mastitis data from Nordic countries were analyzed with milk somatic cell data from non-Nordic countries.

therefore comprise the two runs as described here: Run1 including SC results from all countries and Run2 including CM results from the Nordic countries and SC results from non-Nordic countries. This practice does not utilize the information on SC and $\mathrm{CM}$ from the Nordic countries in an optimal way. In fact, FIN and SWE have separate national evaluations for SC and CM. No SC information is therefore considered in Run2, and no CM information is considered in Run1 from these two countries. DNK analyses SC and CM in a multi-trait model that utilizes the correlated information between the two traits. CM information from DNK is therefore indirectly incorporated into Run1 and SC information from DNK is indirectly incorporated into Run2, though in a suboptimal way.

Having two runs as described here means that many bulls will have two similar, but different, evaluations for SC on the non-Nordic country scales. Mark et al. (2000a) showed that the correlation between SC results in two such runs were higher than 0.97 for all nonNordic countries having two evaluations for SC, but also that differences for single bulls with daughters only in the Nordic countries could be substantial.

A within-country, multiple-trait deregression procedure and a multiple-country, multiple-trait genetic model directly accounting for residual correlations different than zero has been described by Schaeffer (2001). Madsen et al. (2000) introduced an average-information REML algorithm for estimation of (co)variance components for multiple-trait MACE based on a similar model as Schaeffer (2001) proposed. Sullivan and Wilton (2001) proposed a deregressed weighting factor approach to analyze multiple traits from multiple countries, i.e., within-country breeding values are implicitly transformed to a canonical scale during the deregres- sion step. This approach has the advantage of allowing for standard (single-trait) MACE methodology to be used in estimation of genetic parameters and prediction of international breeding values.

Multiple-country, multiple-trait methodology could be implemented to utilize the information related to udder health in a closer to optimal way. The use of the within-country relationships between SC and CM may also help to stabilize the estimation of genetic correlation, since there are usually many more genetic ties between two traits within the same country compared with two traits measured in different countries. The $\mathrm{SC}$ information in the Nordic countries should thus be used to bridge the information on $\mathrm{CM}$ in the Nordic countries with SC information in the countries that do not have national evaluations for CM.

\section{CONCLUSIONS}

High estimated genetic correlations of the order 0.8 or higher were found among milk somatic cell in most countries and the average estimate was 0.85 . For clinical mastitis, trait definitions and/or evaluation procedures were not consistent across countries and estimated correlations ranged between 0.57 and 0.84 . Estimated correlations substantially less than unity could partly be explained by differences in trait definition (e.g., parities) and resulted in some reranking between countries. Many bulls with no daughters in the Nordic countries had low reliabilities for the Nordic clinical mastitis scales, but selection differentials were still higher for international compared with national evaluations. Direct selection for clinical mastitis was also more advantageous in terms of selection response for clinical mastitis compared with indirect selection for 
milk somatic cell. The introduction of routine international genetic evaluations for milk somatic cell and clinical mastitis enables a broader selection of foreign bulls, which comply more closely with true breeding objectives in different countries. Current methodology used for international genetic evaluations could be improved to utilize the genetic relationships between clinical mastitis and milk somatic cell within countries.

\section{ACKNOWLEDGMENTS}

Bert Klei of the American Holstein kindly provided the correlation estimation programs used in this study. The respective national genetic evaluation centers providing data for this study and assisting in the evaluation of results are gratefully acknowledged.

\section{REFERENCES}

Banos, G., G. R. Wiggans, and R. L. Powell. 2001. Impact of paternity errors in cow identification on genetic evaluations and international comparisons. J. Dairy Sci. 84:2523-2529.

Calo, L. L., R. E. McDowell, L. D. VanVleck, and P. D. Miller. 1973. Genetic aspects of beef production among Holstein-Friesians pedigree selected for milk production. J. Anim. Sci. 37:676-682.

Fikse, W. F., and G. Banos. 2001. Weighting factors of sire daughter information in international genetic evaluations. J. Dairy Sci. 84:1759-1767.

Grignola, F., and L. R. Schaeffer. 2000. Relationships between evaluations of Canadian and USA Holstein bulls for longevity and somatic cell score. Livest. Prod. Sci. 65:161.

Groen, A. F., T. Steine, J. J. Colleau, J. Pedersen, J. Pribyl, and N. Reinsch. 1997. Economic values in dairy cattle breeding, with special reference to functional traits. Report of an EAAP-working group. Livest. Prod. Sci. 49:1-21.

Harris, B., and D. Johnson. 1998. Information source reliability method applied to MACE. Interbull Bull. 17:31-36.

Heringstad, B., G. Klemetsdal, and J. Ruane. 2000. Selection for mastitis resistance in dairy cattle: A review with focus on the situation in the Nordic countries. Livest. Prod. Sci. 64:95-106.
Jairath, L., J. M. C. Dekkers, L. R. Schaeffer, Z. Liu, E. B. Burnside, and B. Kolstad. 1998. Genetic evaluation for herd life in Canada. J. Dairy Sci. 81:550-562.

Klei, L., and K. A. Weigel. 1998. A method to estimate correlations among traits in different countries using data on all bulls. Interbull Bull. 17:8-14.

Madsen, P., J. Jensen, and T. Mark. 2000. Reduced rank estimation of (co)-variance components for international evaluations using AI-REML. Interbull Bull. 25:46-50.

Mark, T., W. F. Fikse, G. Banos, U. Emanuelson, and J. Philipsson. 2000a. Summary of MACE pilot-runs for somatic cell count and clinical mastitis. Interbull Bull. 26:43-52.

Mark, T., W. F. Fikse, A. Sigurdsson, and J. Philipsson. 2000b. Feasibility of international genetic evaluations of dairy sires for somatic cell count and clinical mastitis. Interbull Bull. 25:154-162.

Mrode, R. A., and G. J. T. Swanson. 1996. Genetic and statistical properties of somatic cell count and its suitability as an indirect means of reducing the incidence of mastitis in dairy cattle. Anim. Breed. Abstr. 64:847-857.

Mrode, R. A., and G. J. T. Swanson. 1997. Association between somatic cell count progeny tests in the United States of America (USA), The Netherlands and the United Kingdom (UK). Proc. Br. Soc. Anim. Sci. 1997:15.

Nielsen, U. S., G. P. Aamand, and T. Mark. 2000. National genetic evaluation of udder health and other health traits in Denmark. Interbull Bull. 25:143-150.

Rogers, G. W., G. Banos, U. S. Nielsen, and J. Philipsson. 1998 Genetic correlations among somatic cell scores, productive life, and type traits from the United States and udder health measures from Denmark and Sweden. J. Dairy Sci. 81:1445-1453.

Rupp, R., and D. Boichard. 1999. Genetic parameters for clinical mastitis, somatic cell score, production, udder type traits, and milking ease in first lactation Holsteins. J. Dairy Sci. 82:21982204.

Schaeffer, L. R. 1994. Multiple-country comparison of dairy sires. J. Dairy Sci. 77:2671-2678.

Schaeffer, L. R. 2001. Multiple trait international bull comparisons. Livest. Prod. Sci. 69:145-153.

Sigurdsson, A., G. Banos, and J. Philipsson. 1996. Estimation of genetic (co)variance components for international evaluation of dairy bulls. Acta Agric. Scand. Sect. A 46:129-136.

Sullivan, P. G. 1999. Appendix: REML estimation of heterogeneous sire (co)variances for MACE. Interbull Bull. 22:146-148.

Sullivan, P. G., and J. W. Wilton. 2001. Multiple-trait Mace with a number of traits per country. Interbull Bull. 27:68-72. 